\title{
INVESTIGATION ON THE MECHANICAL AND MORPHOLOGICAL PROPERTIES OF FOAMED NANOCOMPOSITES BASED ON WOOD FLOUR/PVC/MULTI-WALLED CARBON NANOTUBE
}

\author{
Afshin Tavassoli Farsheh, ${ }^{a}$ Mohammad Talaeipour, ${ }^{b} *$ Amir Homan Hemmasi, ${ }^{c}$ \\ Habib Khademieslam, ${ }^{b}$ and Ismaeil Ghasemi ${ }^{d}$
}

\begin{abstract}
Recently, the use of nanoparticles in Wood Plastic Composites (WPCs) has been considered by researchers. In this study, Multi-Walled Carbon Nanotubes (MWCNTs) were compounded with PVC, wood-flour, and foaming agent in an internal mixer. The wood flour amount was constant at 40 phr. For CNT and chemical foaming agent, different levels of 0,1 , $2 \mathrm{phr}$ and 0, 3, $6 \mathrm{phr}$ were considered respectively. The samples were foamed via batch process using a compression molding machine at $180^{\circ} \mathrm{C}$. Morphology, density, water absorption, thickness swelling, and tensile properties of foamed composites were evaluated as a function of CNT and chemical foaming agent contents. The experimental results indicated that in the presence of CNT, cell density increased and cell size decreased. Density of the foamed composites was not affected by chemical foaming agent contents. Water absorption and thickness swelling of samples were decreased as compared with wood plastic composite without CNTs. Also, the maximum tensile strength and modulus were increased by up to $20 \%$ and $23 \%$ respectively.
\end{abstract}

Keywords: Composite; Nano; Foam; Multi-Walled Carbon Nanotube; Wood flour; Mechanical properties

Contact information: a: Department of Wood and paper, Science and Research Branch, Islamic Azad University, Tehran, Iran, postal codes: 14515.775; b: Assistant prof., Department of Wood and Paper, Science and Research Branch, Islamic Azad University, Tehran, Iran; c: Associate prof., Department of Wood and Paper, Science \& Research Branch, Islamic Azad University,Tehran, Iran; d: Associate prof., Iran Polymer and Petrochemical Institute, Tehran, Iran.

*Corresponding Author:m.talaeipoor@srbiau.ac.ir

\section{INTRODUCTION}

Wood-based composites have been widely used for several years, but high densities of these composites, compared to natural wood, limit some applications of these engineered materials (Guo 2006; Rizvi et al. 2000). The strategy of foaming wood plastic composites can be a good solution to overcome this disadvantage (Schut 2001). In recent years, an increasing interest in foaming wood polymer composites has been observed (Mengeloglu and Matuana 2003; Bledzki et al. 2005; Bledzki and Faruk 2006). Foaming wood plastic composites offers unique advantages such as decreasing weight and saving material cost (Markarian 2005; Reedy 2002). Faruk et al. (2007) reported that the foaming of wood fiber reinforced composites can improve their ability to withstand repeated nailing and screwing operations compared to unfoamed products of the same composites. It is well known that the physical and mechanical properties of foamed wood plastic composite are closely related to their cellular structures. If the fine-celled 
structures are not distributed evenly within the foams, these properties usually deteriorate (Klempner and Frisch 1991).

With the aim of creating fine cellular structures in wood plastic composite foams and overcoming problems such as mechanical properties destruction (due to density reduction) in foaming processes, researchers have studied many strategies. One good strategy is the use of nano-sized particles (e.g clay and nanotubes) to reinforce WPC foams (Guo et al. 2004; Turng et al. 2003). The presence of nanoparticles may enhance mechanical and physical properties of wood-polymer composites via the improvement of nucleation sites in wood plastic composite during the foaming process. Due to extremely small particle size, it is possible to generate a large number of nucleants with a relatively low particle loading (Lee et al. 2005). Lee et al. (2009) introduced nano-sized clay into wood plastic composite and demonstrated that the addition of nano-clay facilitated the foam expansion and improved the cell morphology.

Carbon nanotubes are another type of promising candidates for the design of novel ultrahigh strength polymer composite foams (Wang et al. 2009; Chen et al. 2010). High flexibility, low mass density, large aspect ratio, high tensile modulus, and great strength of CNTs have the potential to make these nanofillers good candidates in foaming wood plastic composites. It should be considered that the distribution of nanoparticles in WPCs is critical to form fine foam structures with good properties. Faruk and Matuana (2008) examined the use of CNT-reinforced rigid PVC as a matrix for PVC/wood-flour composites. They concluded that with proper CNT dispersion and the use of CNTreinforced PVC as the matrix, the mechanical properties of composites significantly enhanced.

The creation of foamed nanocomposites with CNT and the characterization of their properties (density, cell size, cell density, etc) were the aims of the present paper. In the other word, the effect of adding chemical foaming agents (CFA) and CNTs with different concentration on the foam density, cell size, and cell density of wood/PVC composite was studied. Water absorption and thickness swelling of foamed and unfoamed composites were studied as a function of the foam morphology and CNT concentration. The effect of foaming on the tensile properties of composites with varying concentration of CNT and chemical foaming agent were investigated.

\section{EXPERIMENTAL}

\section{Materials and Methods}

The polymer matrix used in this study was polyvinylchloride (PVC) with a K value of 66, (supplied by Bandare Imam Company). Commercial wood flour of populus (70 mesh-sized, Aria cellulose Co.) was used as a filler. Azodicarbon amide (Anhui Huishang Co.), the exothermic chemical foaming agent, was used to foam wood plastic composites. The multi-walled carbon nanotube used in this study was supplied by Iran Research Institute of Petroleum Industry (RIPI). The outer and inner diameter of the MWCNTs were about 10 and $3.5 \mathrm{~nm}$ respectively, and the purity was $95 \mathrm{wt} \%$.

The heat stabilizer (tin based) with Plasti stab trade name was from Hammond group Inc., and Paraloid k-150 from Rohm and Haas Company was used as processing 
aid in the samples. Zinc oxide from Tianjin First Chemical Co. was used as a catalyst (kicker) to decrease the decomposition temperature of the chemical foaming agent. Its content was fixed at $1.5 \mathrm{phr}$ (parts per hundred) of chemical foaming agent in each treatment.

Formulations of samples are given in Table 1. As can be seen, the concentration of chemical foaming agent and CNT were $0,3,6$ and 0,1 , and 2, respectively, and the wood flour content was fixed at $40 \mathrm{phr}$.

Table1. Formulations used for PVC/CNT Composite Foams

\begin{tabular}{|c|c|}
\hline Ingredients & Concentrations (phr) \\
\hline PVC & 100 \\
\hline Tin-based heat stabilizer & 2 \\
\hline Processing aid & 5 \\
\hline Wood flour & 40 \\
\hline Chemical foaming agents & $0,3,6$ \\
\hline Multi walled carbon nanotube & $0,1,2$ \\
\hline
\end{tabular}

\section{Sample Preparation}

The oven-dried wood-flour, which was prepared at $105^{\circ} \mathrm{C}$ for 24 hours, was dryblended with the PVC, ZnO, stabilizer, and processing aid in a turbo mixer for 5 minutes. The turbo mixer was a product of Kim Engineering Machine Co. The formulations were then mixed in a $45 \mathrm{~mL}$ electrically-heated internal mixer with roller style mixing blades. The mixer was a product of Brabender Plasti Corder Co. The temperature of the internal mixer was fixed at $150{ }^{\circ} \mathrm{C}$ throughout the experiments. This temperature was below the decomposition temperature of the chemical foaming agent. Internal rotor speed was 60 $\mathrm{rpm}$, and a $5-\mathrm{kg}$ dead weight was put on the top of the ram.

Mixing of the above ingredients was started in the internal mixer in order to follow the fusion curve. Melting started, and after two minutes when the material reached a void free state and equilibrium torque was reached, CNTs were added to the internal mixer. The mixing process continued, and after 1 minute, the third minute of mixing, chemical foaming agent was added to the internal mixer. The mixing process took 7 minutes. The similar procedure has been reported by Faruk and Matuana (2008) for the preparation of $\mathrm{PVC} / \mathrm{CNT}$ nanocomposites.

Melted mixtures from the internal mixer at different treatments were put into a mold and then were compression-molded with a Toyo Seiki Press into test samples at $180^{\circ} \mathrm{C}$ and $25 \mathrm{MPa}$ constant pressure for 15 minutes.

After 15 minutes the press temperature was reduced to a degree below $100^{\circ} \mathrm{C}$ by circulating water around the press plates. After the cooling, pressure was released to the atmospheric pressure to induce a sudden thermodynamic instability in the polymer/gas solution, and the foams were formed.

\section{Determinations}

Foam morphology (cell size \& cell density) was characterized using scanning electron microscopy (SEM, LEO Oxford). Foamed composites were freeze-fractured in liquid nitrogen, and the fracture surface was sputter-coated with gold. The SEM pictures 
were analyzed by Corel DRAW software (version 12) to determine cell size and cell density.

Cell density $\left(N_{f}\right)$, in terms of number of cells per $\mathrm{cm}^{3}$, can be expressed by Eq. 1 (Goel et al. 1994),

$$
N_{f}=\left(n M^{2} / A\right)^{3 / 2}
$$

where $A$ is the area $\left(\mathrm{cm}^{2}\right)$ of the SEM micrograph, $M$ is the magnification factor, and $n$ is the number of cells in the SEM micrograph.

Potential nucleant densities of CNTs in a heterogenous WPCs foam systems were calculated by Eq (2) (Shen et al. 2005),

$$
\text { Nucleant per } \mathrm{cm}^{3}=W / \rho_{p} \times \rho_{\text {blend }} / v_{p}
$$

where $W$ is the weight fraction of the particle in the composite, $\rho_{p}$ is the density of the particle, $\rho_{\text {blend }}$ is the density of the polymer blend, and $v_{p}$ is the volume of the individual particle.

The nucleation efficiency of CNTs was calculated by the ratio of the measured cell density to the potential nucleant density.

The densities of foamed and un-foamed composites were determined by averaging the mass per volume data. Measurement results of five specimens per sample were obtained following the procedure described in ASTM-D 1622-98. For water absorption tests, five specimens of each composite were selected and dried in an oven for $24 \mathrm{~h}$ at $102 \pm 3^{\circ} \mathrm{C}$. The weight of dried specimens was measured with the precision of $0.001 \mathrm{~g}$. The specimens were then placed in distilled water and kept at room temperature. The specimens were removed from the water and the surface water was wiped off using blotting paper. The weight of the specimens was measured at different times. The values of the water absorption were calculated in percentage using Eq. 3,

$$
W=\left[\left(W_{t}-W_{o}\right) / W_{o}\right] \times 100 \%
$$

where $W_{t}$ is the weight of the specimen at a given immersion time and $W_{o}$ is the ovendried weight.

A similar procedure for water absorption was applied to determine the thickness swelling of samples. Thickness of the specimens was measured at different times. The values of the thickness swelling in percentage were calculated using Eq. 4,

$$
T S(t)=\left[\left(T(t)-T_{o}\right) / T_{o}\right] \times 100 \%
$$

where TS $(t)$ is the thickness swelling at time $t, T_{o}$ is the initial thickness of specimens, and $T(t)$ is the thickness at time $t$.

The tensile tests were conducted using a Zwick Z250 device at test speeds of 5 $\mathrm{mm} / \mathrm{min}$ according to ASTM standards D 638. Statistical analysis was conducted using SPSS software (Version 12) as analysis of variance. Also, the Duncan multiple range test (DMRT) was used to test the statistical significance at $\alpha=0.05$ level. 


\section{RESULTS AND DISCUSSION}

To interpret the results, it is useful to start by describing the foam morphology. Table 2 shows the cell size and cell density of the samples.

Table 2. Cell Size and Cell Density of Rigid PVC/wood Flour Composite Foams

\begin{tabular}{|c|c|c|}
\hline Formulation(phr) & Cell Size $(\mu \mathrm{m})$ & $\begin{array}{c}\text { Average Cell Density } \\
\left(\mathrm{cells} / \mathrm{cm}^{3}\right)\end{array}$ \\
\hline 0 CNT/ 3 CFA & 11.03 & $1.1 \times 10^{7}$ \\
\hline 0 CNT/ 6 CFA & 14.36 & $2 \times 10^{7}$ \\
\hline 1 CNT/ 3 CFA & 10.88 & $2.19 \times 10^{7}$ \\
\hline 1 CNT/ 6 CFA & 11.5 & $3.3 \times 10^{7}$ \\
\hline 2 CNT/ 3 CFA & 5 & $2.4 \times 10^{8}$ \\
\hline 2 CNT/ 6 CFA & 6.17 & $8 \times 10^{7}$ \\
\hline
\end{tabular}

* Chemical foaming agent

At the constant chemical foaming agent concentration, with the increase of the CNTs, the cell size of wood plastic composite foams were decreased and their cell density increased.

As the chemical foaming agent concentration increased from 3 to $6 \mathrm{phr}$ and the CNTs levels were 0 and $1 \mathrm{phr}$, the average cell density increased. This is expectable because more foaming agent concentration means more production of $\mathrm{N}_{2}$ and $\mathrm{CO}$ in the compound that is the production of thermal decomposition of the azodicarbonamide. Consequently, the number of nucleated cells per unit volume and cell growth were increased (Zakaria et al. 2009). Also, the average cell sizes developed in the foamed nanocomposites were not significantly affected by chemical foaming agent contents.

When the chemical foaming agent concentration was increased from 3 to $6 \mathrm{phr}$ and the CNTs level was increased to 2, the cell density decreased. This is probably due to the imperfect dispersion of CNTs in polymer matrix and probably due to the cell coalescence, which was brought about by increasing the foaming agent concentration.

The results showed that by the incorporation of CNTs into the compound, the cell size decreased, as shown in Table 2. When compared to the pure WPCs foams, the addition of $2 \mathrm{phr}$ CNTs yielded an increase of cell density up to $2.4 \times 10^{8}$, while the cell size decreased to $5 \mu \mathrm{m}$. This is due to the extremely fine dimensions and large surface area of CNTs that help create more nucleation centers in the polymer and at the polymer/wood interface; consequently, there is less amount of gas available for bubble growth, which leads to cell size reduction and cell density improvement.

Measured cell density, potential nucleation density, and nucleation efficiencies of CNTs are given in Table 3. As can be seen, at constant chemical foaming agent concentration, increasing the CNTs from 1 to $2 \mathrm{phr}$ led to improved nucleation efficiencies. This finding implies that CNTs can effectively induce the nucleation of a large amount of bubbles, but efficiency of this nucleation may be affected by nanodispersion. 
Table 3. Comparison of Potential Nucleant Density and Actual Cell Density

\begin{tabular}{|c|c|c|c|}
\hline $\begin{array}{c}\text { Formulation } \\
(\mathrm{phr})\end{array}$ & $\begin{array}{c}\text { Measured cell density } \\
\left(\mathrm{cell}^{\prime} \mathrm{cm}^{3}\right)\end{array}$ & $\begin{array}{c}\text { Potential nucleant density } \\
\left(\mathrm{cells} / \mathrm{cm}^{3}\right)\end{array}$ & $\begin{array}{c}\text { Nucleation efficiency } \\
(\%)\end{array}$ \\
\hline 1 CNT/ 3 CFA & $2.19 \times 10^{7}$ & $4.14 \times 10^{12}$ & $5.28 \times 10^{-4}$ \\
\hline 2 CNT/ 3 CFA & $2.4 \times 10^{8}$ & $7.53 \times 10^{12}$ & $3.18 \times 10^{-3}$ \\
\hline 1 CNT/ 6 CFA & $3.3 \times 10^{7}$ & $3.89 \times 10^{12}$ & $8.48 \times 10^{-4}$ \\
\hline 2 CNT/ 6 CFA & $8 \times 10^{7}$ & $7.5 \times 10^{12}$ & $1.06 \times 10^{-3}$ \\
\hline
\end{tabular}

In foaming wood plastic composites, the highest nucleation efficiency can be achieved if nucleants are finely dispersed at the polymer-wood matrix interface (Guo et al. 2008). Results showed that the potential nucleant densities of CNTs were much higher than the measured cell densities, which implies an imperfect dispersion of CNTs in the polymer matrix (Table 3 ).

Typical SEM micrographs of samples are shown in Fig. 1.
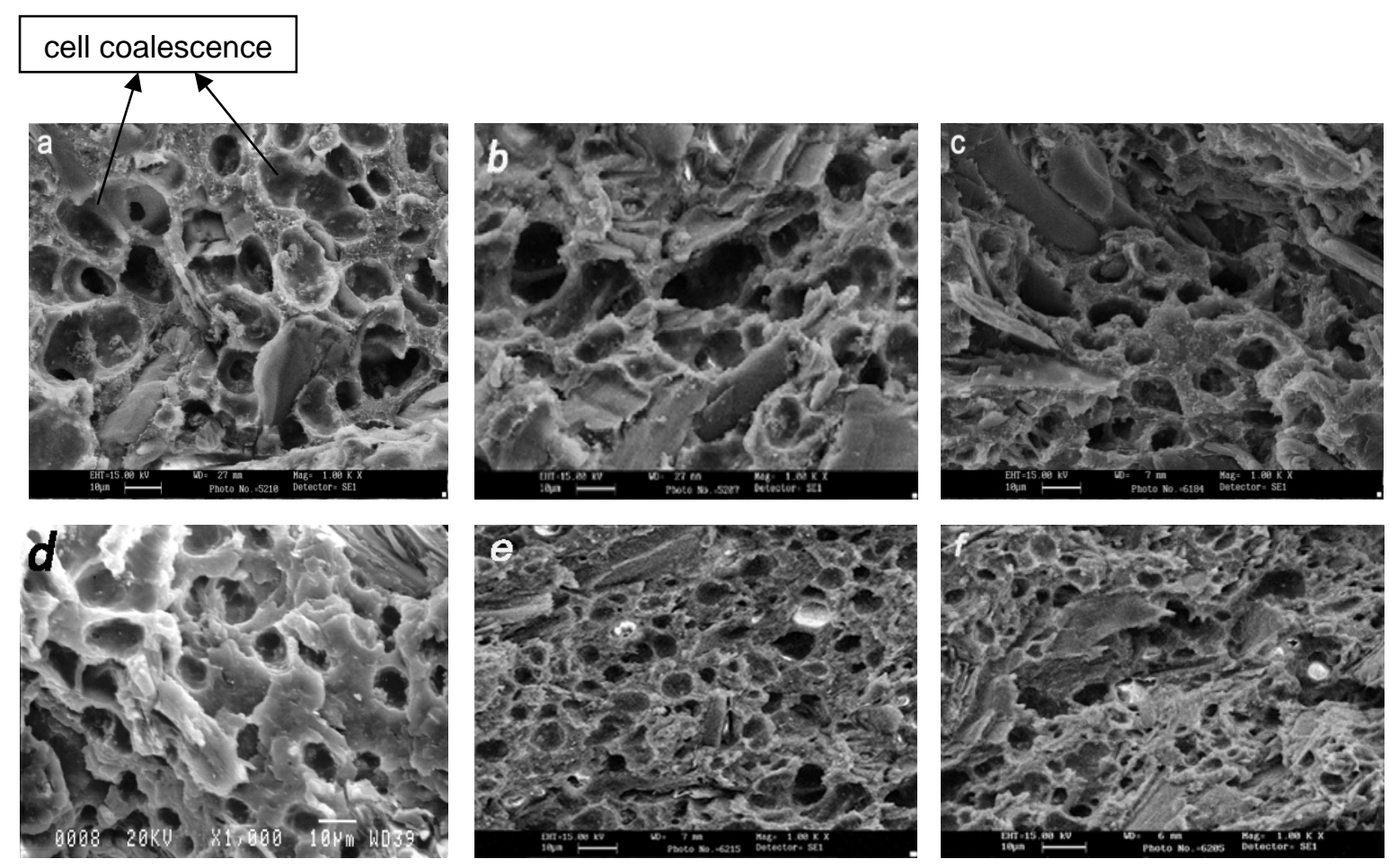

Fig.1. SEM micrographs of foams: ((a) 0 phr CNT/6 phr CFA, (b) 0 phr CNT/3 phr CFA, (c) 1 phr CNT/3 phr CFA, (d) 1 phr CNT/6 phr CFA, (e) 2 phr CNT/6 phr CFA, (f) 2 phr CNT/3 phr CFA, wood fiber content 40 phr; scale bars $=10 \mu \mathrm{m}$; magnification $=1000$ ).

These figures show the cell size and the morphology of the samples, which were affected by nanoparticles and chemical foaming agent. The aforesaid trend for changing these parameters is observed in these figures. At $6 \mathrm{phr}$ chemical foaming agent, the gas concentration was enough for the bubble growth and in some regions cell coalescence happened (Fig. 1a). 
Figure 2 illustrates the effect of chemical foaming agent and CNT concentration on the density of both foamed and unfoamed composites. Chemical foaming agent and CNTs had significant effect on density reduction of wood/PVC composites according to analysis of variance.

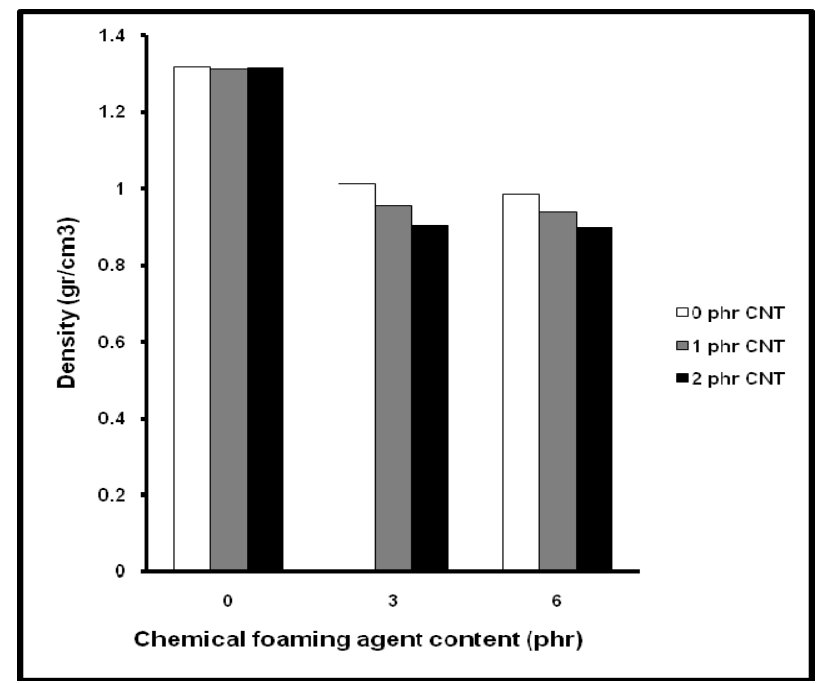

Fig. 2. Influence of chemical foaming agent and CNT content on density of composites

In composites without CNTs, addition of $3 \mathrm{phr}$ chemical foaming agent decreased the density by up to $23 \%$ (from $1.314 \mathrm{gr} / \mathrm{cm}^{3}$ to $1.012 \mathrm{gr} / \mathrm{cm}^{3}$ ). At this chemical foaming agent content, addition of $1 \mathrm{phr}$ and $2 \mathrm{phr}$ of CNTs led to density reduction by up to $27 \%$ and $31 \%$ respectively (Fig. 2).

In the other words, by the addition of multi-walled carbon nanotubes to wood-PVC composites, cell density was increased (Table 2). This is because of more bubble nucleation by nanoparticles, which caused the increase of cells and the decrease of composite density (Fu and Naguib 2006).

Variance analysis of the density results showed that chemical foaming agent had a significant effect $(\mathrm{P}<0.05)$ on density reduction of foamed composites compared to similar unfoamed samples, but the Duncan test revealed that the density of the foamed composites was not affected significantly by chemical foaming agent contents, and both densities were put in one group. So it can be concluded that the best density reduction can be obtained with 3 phr chemical foaming agent and 2 phr multi-walled carbon nanotubes. This result was in accordance with the cell density result obtained from Table 2.

Figure $3(\mathrm{a} \& \mathrm{~b})$ and Fig. $4(\mathrm{a} \& \mathrm{~b})$ show the water absorption and thickness swelling of foamed and unfoamed composites after 2 and 24 hs respectively.

Compared to unfoamed specimens, the foamed composites showed higher water absorption and thickness swelling, and sometimes these rates were approximately two times higher than the unfoamed specimens. Water absorption and thickness swelling were affected by cell density and cell size. In fact, the void content was increased by the addition of chemical foaming agent (Table 2); consequently, water uptake and thickness swelling increased. 

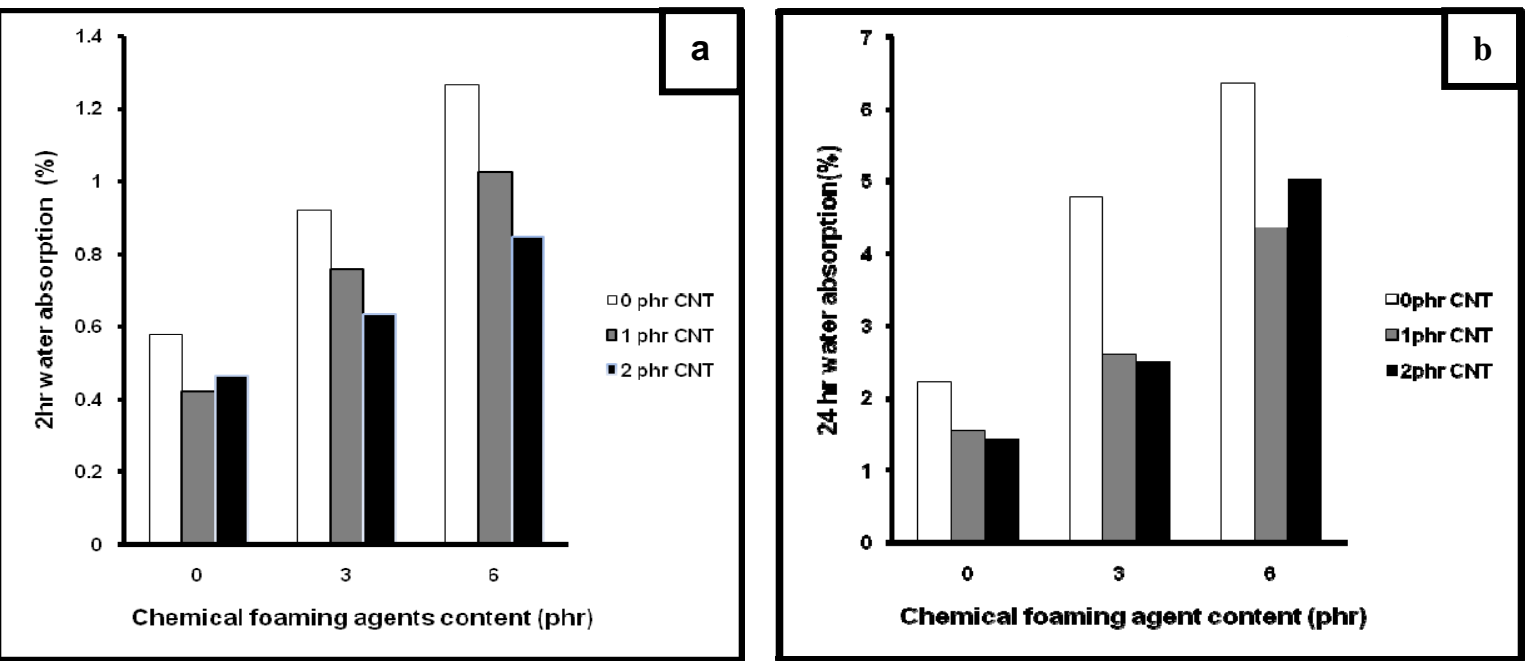

Fig. 3. Water absorption of foamed and unfoamed composites
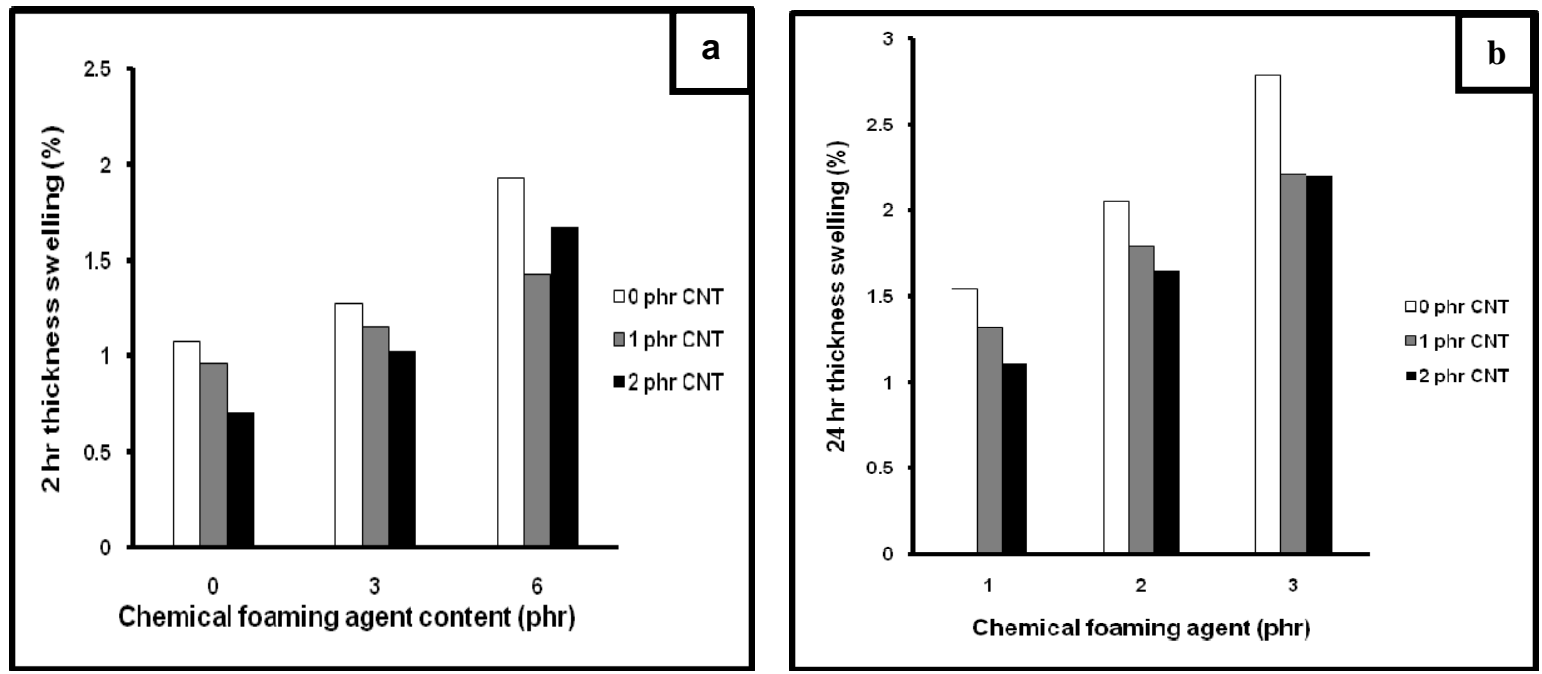

Fig. 4. Thickness swelling of foamed and unfoamed composites

By the addition of CNTs to wood-polymer composites, water absorption and thickness swelling were decreased in comparison to wood plastic composites samples without CNTs. This is because of hydrophobic and water repelling nature of CNTs. In a short soaking time $(2 \mathrm{hr}$ ), the prevailing factor that affected the water absorption and thickness swelling of nanocomposites was the hydrophobic nature of multi-walled carbon nanotubes (Fig. 3a), but as the soaking time increased ( $24 \mathrm{hr}$ ), more water penetrated to hollow voids, and the water absorption of nanocomposite containing $2 \mathrm{phr}$ CNTs (higher cell density) increased. It can be concluded that in foamed nanocomposites, the influence of cell size and cell density on water absorption and thickness swelling is more important at higher soaking times. 
The tensile strengths of unfoamed and foamed samples are shown in Fig. 5. As expected, the tensile strength of wood plastic composites was reduced by foaming, regardless of the CNTs content.

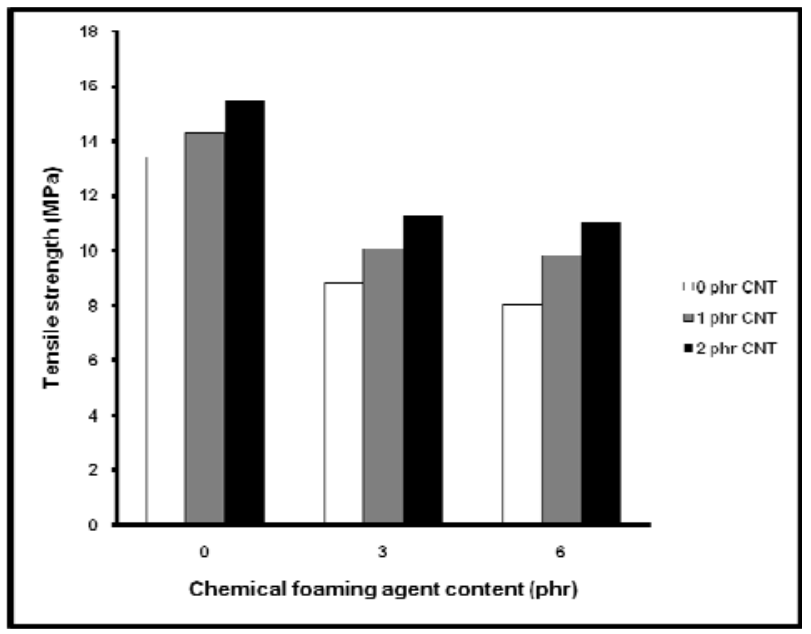

Fig. 5. Influence of chemical foaming agent and CNT content on tensile strength of composites

Due to the high aspect ratio and large surface area of CNTs, the tensile strength of sample containing nanoparticles was increased. The results revealed that the addition of CNTs at a level of $2 \mathrm{phr}$ led to the increase of the tensile strength by up to $20 \%$. A typical SEM micrograph, showing the status of dispersion of nanoparticles (as reinforcing agent) in the polymeric matrix is given in Fig. 6.

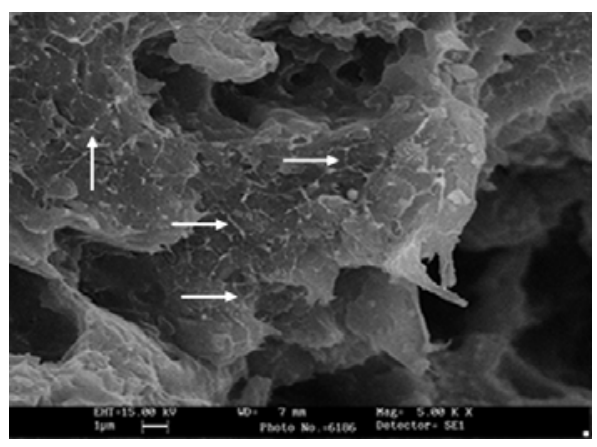

Fig. 6. SEM picture of wood plastic foams reinforced with carbon nanotubes

This trend for tensile strength can be explained as follows: multi-walled carbon nanotubes can affectively induce the nucleation of a large amount of bubbles, and consequently cell densities of foamed wood plastic composites increased. As the cell densities increased, cell sizes decreased to less than 6 microns. These too small microspheres can contribute to transfer the applied stress and to increase the tensile strengths. As a general rule, tensile strengths decreased as the foaming agents increased. These trends may be due to the increased bubble nucleation and probably due to cell coalescence, which was brought about by increasing the foaming agent concentration. 
Figure 7 illustrates the changes in tensile modulus of foamed and unfoamed rigid $\mathrm{PVC} /$ wood-flour nanocomposites.

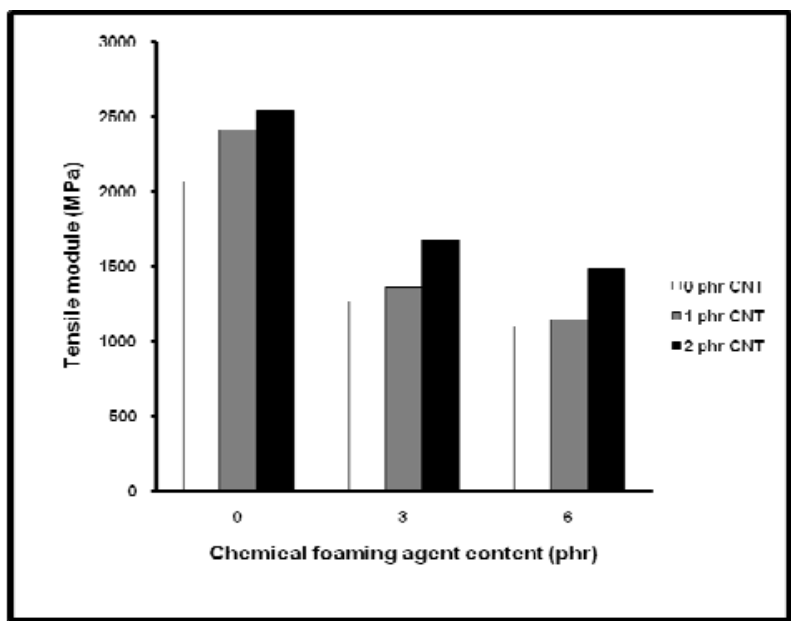

Fig. 7. Influence of chemical foaming agent and CNT content on tensile modulus of composites

Generally, by foaming wood plastic composites, the tensile modulus was decreased. As seen, at constant concentration of chemical foaming agent, addition of CNTs led to the improvement of the tensile modulus. However, at constant CNTs content, addition of more chemical foaming agent led to a reduction of tensile modulus.

\section{CONCLUSIONS}

The use of multi-walled carbon nanotubes to reinforce rigid PVC/wood flour composites foams was examined. First, the effect of CNTs and foaming agent contents on foam morphology (cell size, cell density) of composite foams was evaluated. Second, the influence of added CNTs on foam density and some physical and mechanical properties of nanocomposites were examined. The following conclusions can be drawn:

1. Compared to composites without carbon nanotubes (CNTs), in the presence of CNTs, cell densities of wood/plastic foams were increased and cell sizes were decreased.

2. By using CNTs it was possible to create very good cellular structures in wood-plastic composites by the compression molding technique.

3. The density of the samples was not affected by the content of chemical foaming agent. As the CNT contents were increased to $2 \mathrm{phr}$, the foam density decreased, which shows the effect of CNTs on increase of the bubble nucleation in the wood polymer foams.

4. By the addition of CNTs to compound, water absorption and thickness swelling of foamed samples decreased in comparison to samples without CNTs.

5. Compared to the pure wood plastic composites, the addition of CNTs resulted in an increase of tensile strength. For foamed nanocomposite samples, addition of CNTs at a $2 \mathrm{phr}$ level led to the increase of the tensile strength up to $20 \%$ and this led to the improvement of the tensile modulus by nearly $23 \%$. 


\section{ACKNOWLEDGMENTS}

This article is derived from a doctoral thesis of Afshin Tavassoli Farsheh (Ph.D Student of Islamic Azad University, Science and Research Branch of Tehran) entitled, Investigation on the Morphological, Density and Tensile Strength of Foamed Hybrid Nano Composite Based on PVC/Wood-flour and Carbon Nanotube. The authors appreciate the support received from the Islamic Azad University, Science and Research Branch of Tehran.

\section{REFERENCES CITED}

Bledzki, A. K., and Faruk, O. (2006). "Injection molded microcellular wood fiberpolypropylene composites," Composite J. 37, 1358-1367.

Bledzki, A. K., Zhang, W., and Faruk, O. (2005). "Micro foaming of flax and wood fiber reinforced polypropylene composites," Holz J. 63, 30-37.

Chen, L., Ozisik, R., and Schadler, L. S. (2010). "The influence of carbon nanotube aspect ratio on the foam morphology of MWNT/PMMA nano composite foams," Polymer J. 51 2368-2375.

Faruk, O., Bledzki, A. K., and Matuana, L. M. (2007). "Microcellular foamed woodplastic composites by different process," Macromolecular Materials and Engineering J. 292, 113-127.

Faruk, O., and Matuana, L. M. (2008). "Reinforcement of rigid PVC/wood-flour Composites with multi-walled carbon nanotubes," Vinyl \& Additive Technol. J. 14, 60-64.

Fu, J., and Naguib, H. E. (2006). "Effect of nanoclay on the mechanical properties of PMMA/clay nano composite foams," Cellular Plastics J. 42, 325-342.

Goel, S. K., and Beckman, E. J (1994). "Generation of microcellular polymeric foams using supercritical carbon dioxide: effect of pressure and temperature on nucleation," Polymer Engineering\& Science J. 34, 1137-1147.

Guo, G. (2006). "Development of fine-celled bio-fiber composite foams using physical blowing agents and nano particles," PhD Thesis. University of Toronto, Department of Mechanical \& Industrial Engineering, p.5.

Guo, G., Rizvi, G. M., and Park, C. B. (2008). "Wood-polymer composite foams," WoodPolymer Composites, Woodhead Publishing Limited, England, 227-253.

Klempner, D., and Frisch, K. C. (1991). Handbook of Polymer Foams and Foam Technology, Hanser, Munich.

Lee, Y. H., Sain, M., Kuboki, T., and Park, C. B. (2009). "Extrusion foaming of nanoclay filled wood fiber composites for automotive applications," Material and Manufacturing J. 1, 641-647.

Lee, L. J., Zeng, C., Cao, X., Han, X., Shen, J., and Xu, G. (2005). "Polymer nano composite foams," Composite Science and Technology J. 65, 2344-2363.

Markarian, J. (2005). "Wood-plastic composites: Current trends in materials and processing," Plastics, Additives and Compounding J. 7(5), 20-26. 
Mengeloglu, F., and Matuana, L. M. (2003). "Foaming of rigid PVC /wood-flour composites through a continuous extrusion process," Vinyl Additive Technology J. 9, 26-31.

Reedy, M. (2002). "New chemical foaming agents expand wood/plastic composite market," Plastics, Additives and Compounding J. 4(5), 24-26.

Rizvi, G., Matuana, L. M., and Park, C. B. (2000). "Foaming of PS/wood fiber composites using moisture as a blowing agent," Polymer Engineering and Science J. 40, 2124-2132.

Schut, J. H. (2001). "Foaming expands possibilities for wood-fiber composites," Plastic technology (www.ptonline.com/articles/200107fa2.html).

Shen, J., Zeng, C., and Lee, L. (2005). "Synthesis of polystyrene-carbon nano fibers nano composite foams," Polymer J. 46, 5218-5224.

Turng, L. S., Yuan, M., Kharbas, H., Winata, H., and Caulfield, D. F. (2003).

"Application of nano composites and wood fiber plastic for microcellular injection molding," Paper presented at the Proceeding of International Wood fiber-Plastic Composites Conferences, Wisconsin, USA.

Wang, S. H., Liang, R., Wang, B., and Zhang, C. (2009). "Covalent addition of diethyl toluene diamines onto carbon nanotubes for composite application," Polymer Composites J. 30, 1050-1075.

Zakaria, Z., Ariff, Z. M., and Sipaut, C. S. (2009). "Effects of parameter changes on the structure and properties of low-density polyethylene foam," Vinyl Additive Technology J. 15, 120-128.

Zeng, C., Hossieny, N., Zhang, C. H., and Wang, B. (2010). "Synthesis and processing of PMMA carbon nanotube nano composite foams,” Polymer J. 51, 655-664.

Article submitted: October 31, 2010; Peer review completed: December 26, 2010;

Revised version received and accepted: January 22, 2011 ; Published: January 25, 2011. 